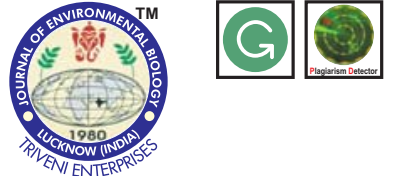

DOI : http://doi.org/10.22438/jeb/38/4/MRN-339

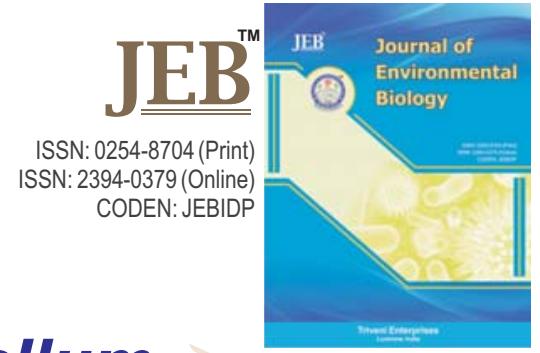

\title{
Bioprospecting the fungicides compatible Trichoderma asperellum isolate effective against multiple plant pathogens in vitro
}

Authors Info

M. Manjunath ${ }^{*}$, A. Singh", A. N. Tripathi', R. Prasanna', A.B. Rai' and B. Singh ${ }^{1}$

'Division of Crop Protection, ICARIndian Institute of Vegetable Research, Varanasi-221 305, India

${ }^{2}$ Division of Microbiology, ICARIndian Agricultural Research Institute, New Delhi-110 012, India

${ }^{*}$ Corresponding Author Email : manjumbl@gmail.com

\section{Key words}

Biocontrol agent,

Fungicides,

ITS Primers,

Phytopathogenic fungi ,

Trichoderma

Publication Info

Paper received : 27.04 .2016

Revised received : 16.08 .2016

Re-revised received : 15.11 .2016

Accepted:01.12.2016
Abstract

Aim: It is essential to develop an efficient ecofriendly disease management programme which helps in gradual reduction in use of harmful chemicals. The objective of the study was to isolate, purify and identify Trichoderma isolate from diseased plant tissues and to identify its compatibility with commonly used fungicides for the eco-friendly management of vegetable diseases.

Methodology: Trichoderma asperellum was isolated from Sclerotinia sclerotiorum infected stem tissues of pea on potato dextrose agar. The morphological, cultural characteristics and molecular identification of Trichoderma asperellum was carried out using ITS primers. In vitro antagonistic efficiency of Trichoderma asperellum was studied against phytopathogenic fungi viz., Pythium aphanidermatum, Pythium debaryanum, Sclerotium rolfsii Sr1, Sclerotium rolfsii Sr3, Fusarium oxysporum f.sp. lycopersici and Alternaria solani.

Results: The nucleotide sequence of amplified ITS region was deposited at Genbank (NCBI) with accession no. KT824429. The highest mycelial inhibition values of $43.57,38.16,42.56$ and $54.87 \%$ were obtained for Pythium aphanidermatum, $P$. debaryanum, Sclerotium rolfsii Sr1 and Sclerotium rolfsii $\mathrm{Sr} 3$, respectively, after 6 days of $T$. asperellum inoculation. T. asperellum exhibited $100 \%$ compatibility with $\mathrm{M}$ a $\mathrm{n} \mathrm{c} O \mathrm{z}$ e b. A zoxystrobin, Cymoxinil+Mancozeb Metalxyl+Mancozeb at 100, 200 and 300 ppm. $\mathrm{Th}$ e per cent compatibility of 98.15 , 74.82 and 50.38 with Carbendazim at 100 , 200 and 300 ppm was also recorded.

Interpretation : These studies established the aggressive nature of the isolate and its suitability in integrated disease management practices.

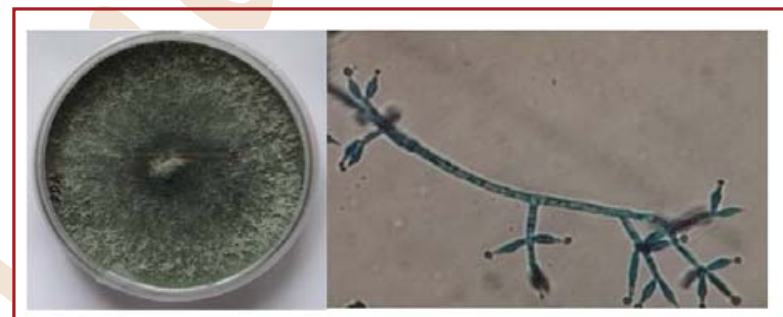

Morphological and microscopic view of Trichoderma asperellum

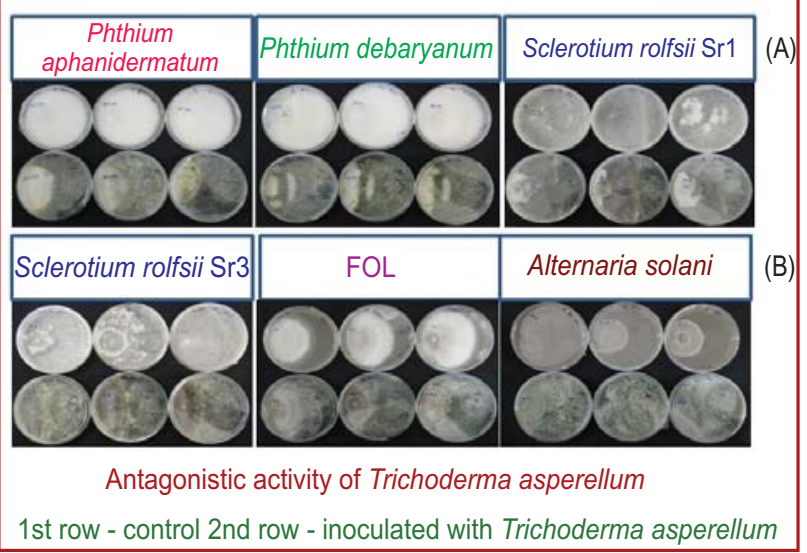




\section{Introduction}

The increased environmental pollution due to application of agricultural chemicals for enhancing crop productivity emphasized the need for alternative methods to manage soil borne diseases and to sustain agricultural production systems (Kamal et al., 2009; Holajjer et al., 2013; Pokhare et al., 2015). Biological control is an effective option to minimize the use of expensive chemical fungicides in modern agriculture, as they are the main cause of resistance development in pathogens besides polluting the environment (Harman et al., 2004). In recent years, utilization of Trichoderma has been encouraged as an ecofriendly measure to protect the plants from diseases and increase the yields (Mukherjee et al., 2012). Genus Trichoderma has helped to sustain the agricultural yields naturally, as a multifunctional agent (Hamed et al., 2015; Triveni et al., 2015). This ubiquitous and freeliving filamentous fungus, with high survival rate, reproductive ability, nutrient use and capacity to promote plant growth through diverse mechanisms, has several species that are effective biological control agents against plant pathogens (Brito et al., 2014, Abo-Elyousr et al., 2014; Dubey et al., 2001; Zhang et al., 2013). It is being used in several crops like vegetables, pulses, rice, wheat, groundnut, soybean, sugarcane, sunflower, ginger, cardamom, black pepper, coconut, cotton, castor, banana and tobacco against different plant pathogens (Sriram et al., 2013; Rao et al., 2015).

To develop an efficient disease management programme, compatibility of potential bioagents with fungicides is essential (Thoudam and Dutta, 2014). Diseases can be effectively managed by using potential bioagent which is tolerant to fungicides and keeps pathogens under sufficient pressure (Wedajo, 2015). The combination of biocontrol agents with fungicides is expected to provide the same level of disease suppression, as that of with higher fungicide use and diminish the possibility of resistance development in pathogens (Thoudam and Dutta 2014; Bhai et al., 2010). In addition to this, it also extends the duration of active disease control (Hjeljord and Tronosmo, 1998). Integration of bioagents which are compatible with fungicides in disease management is very important. Exploration of more effective Trichoderma strains with high antagonistic potential required for successful biological control programmes under different ecological niche (El Komy et al., 2015). The objective of the present investigation included isolation and characterization of Trichoderma asperellum and its in vitro compatabilty with commonly used fungicides in disease control.

\section{Materials and Methods}

Study area : The study was conducted at ICAR-Indian Institute of Vegetable Research, Varanasi, India having average rainfall of $1000 \mathrm{~mm}$. In general, the temperature ranged from $5^{\circ} \mathrm{C}$ to $42^{\circ} \mathrm{C}$, January being coldest and May-June hot.
Collection, isolation, purification of Trichoderma isolate : Sclerotinia sclerotiorum infected stem tissues of pea were collected during January 2015, from the research farm of ICARIndian Institute of Vegetable Research, Varanasi. The diseased tissues (approx. 30-40 g) were surface sterilized with 1\% sodium hypochlorite solution for one minute. Then, the samples were rinsed with sterile distilled water for 6 times, air dried and placed on potato dextrose agar (PDA) medium, supplemented with 100 $\mathrm{mg} / \mathrm{l}$ streptomycin sulphate. The plates were kept in a BOD for 6 days at $28{ }^{\circ} \mathrm{C}$. Along with Sclerotinia growth green coloured mycelia were observed, which was selected and reinoculated on PDA plate. The fungus was purified by mycelial tip method and maintained on PDA slants at $4^{\circ} \mathrm{C}$ for further use.

Cultural and morphological characterization : The morphological and cultural characteristics of Trichoderma asperellum isolate was studied in four different media viz., PDA, Corn Meal Agar(CMA), Oat Meal Agar (OMA) and Czapek dox agar medium (Shaiesta et al., 2012). Mycelial discs (5 mm) of young growing culture of Trichoderma isolate was inoculated in the periphery of Petri plates containing previously mentioned media and incubated at $28 \pm 2{ }^{\circ} \mathrm{C}$ for $72 \mathrm{hrs}$. The growth of mycelium was recorded at 24,48 and $72 \mathrm{hrs}$. The experiment was repeated thrice with three replications.

Molecular identification and phylogenetic analysis: Trichoderma asperellum was grown on potato dextrose broth for seven days at $28 \pm 1^{\circ} \mathrm{C}$ in a BOD incubator. The fungal genomic DNA was extracted (Doyle and Doyle, 1987) and the internal transcribed spacer (ITS) regions were amplified by PCR using universal primers ITS4 (TCCTCCGCTTATTGATATGC) and ITS5 (GGAAGTAAAAGTCGTAACAAGG) (White et al., 1990). The PCRs were performed in a $25 \mu$ l reaction volume containing $16 \mu \mathrm{l}$ PCR grade water (Sigma), $2.5 \mu$ l PCR buffer (10x), $2.5 \mu$ l of $10 \mathrm{mM}$ dNTPs mix (Sigma-Aldrich), $1 \mu$ l of each primer (20 pmol $\left.\mu^{-1}\right), 1 \mu \mathrm{l}$ $\left(5 \mathrm{U \mu}^{-1}\right)$ of Taq polymerase (Sigma-Aldrich) along with 20-50 $\mathrm{ng}$ of template DNA. PCR was performed in an Eppendorf Master Cycler (Eppendorf, Hamburg). The amplification program consisted of an initial denaturation step at $95^{\circ} \mathrm{C}$ for 5 min followed by 30 cycles of denaturation at $95^{\circ} \mathrm{C}$ for $1 \mathrm{~min}$, annealing for 30 seconds at $55^{\circ} \mathrm{C}$ and extension for $1 \mathrm{~min}$ at $72{ }^{\circ} \mathrm{C}$. A final extension step at $72^{\circ} \mathrm{C}$ for $7 \mathrm{~min}$ was included at the end of the amplification. All PCR products were electrophoresed, imaged and analyzed in a Gel Documentation System (Syngene Inc. Cambridge).

The PCR products prior to sequencing were purified using Axygen Spin PCR clean-up kit. Sequencing reaction was performed using the Big Dye Terminator cycle sequencing kit $(A B I)$ on a thermal cycler with respective primers. The amplification products were cleaned by ammonium acetate precipitation. The cleaned product was finally run (after addition of HiDi formamide) on an automated ABI (3100Avante) DNA sequencer to get sequences in $A B I$ format at National Fungal 
Culture collection of India (NFCCI), Pune. The PCR fragment was sequenced using $A B I 3100$ automated DNA sequencer. The sequence was compared using $\mathrm{NCBI}$ (www.ncbi.nlm.nih.gov) blast search, to determine percentage sequence identity/similarity with those species that showed maximum identity in blast search. The sequences showing highest scores with the present isolate were obtained from database and aligned using the Clustal W program (Thompson et al., 1994). The phylogenetic tree was generated by MEGA 5 software using the neighbour joining method with 1000 bootstrapped replications to estimate evolutionary distances between all pairs of sequences simultaneously (Tamura et al., 2011).

In vitro antagonistic studies : In vitro confrontations were studied between the Trichoderma asperellum and the phytopathogenic fungi: Pythium aphanidermatum and Pythium debaryanum collected from the Indian Type Culture Collection, New Delhi; Sclerotium rolfsii Sr1, Sclerotium rolfsii Sr3, Fusarium oxysporum f.sp. Iycopersici and Alternaria solani were taken from the germplasm of ICAR-Indian Institute of Vegetable Research, Varanasi. All these fungi are important pathogens in vegetables. The isolate of $T$. asperellum was tested against the phytopathogens using dual culture method (Morton and Stroube, 1955). Each Petri-dish $(9 \mathrm{~cm})$ containing PDA was inoculated with two $5 \mathrm{~mm}$ diameter mycelial discs i.e., one of the pathogen and one of $T$. asperellum were placed at $7 \mathrm{~cm}$ distant from each other. The discs containing pathogenic fungi were placed in the Petridishes, 2 days before the Trichoderma discs. For control treatments, a disc of individual pathogen was placed on separate PDA medium. The inoculum discs were obtained from the margin of actively growing 6 day old fungal cultures. Three replicates were maintained for each treatment. Plates were incubated at $28 \pm 2^{\circ} \mathrm{C}$ for 10 days. The experiment was conducted by following completely randomized design. Percent inhibition was calculated by the following formula i.e., $\mathrm{I}=(\mathrm{C}-\mathrm{T} / \mathrm{C}) \times 100$, where, $\mathrm{I}$ is percent inhibition, $C$ is radial growth of pathogen $(\mathrm{cm})$ alone (control), $T$ is radial growth of pathogen $(\mathrm{cm})$ in the presence of Trichoderma isolate (Edington et al., 1971). The microscopic observations were recorded at $40 \mathrm{X}$ for possible mycoparasitism at interaction zone between two fungal cultures.

Compatibility with fungicides : The effect of different fungicides on mycelial growth of Trichoderma asperellum was evaluated in vitro (Nene and Thapliyal, 1993). Each and every fungicide was separately added to molten and cooled sterilized PDA media (Himedia, India) to get the concentration of 100, 200 and 300 ppm and poured into $90 \mathrm{~mm}$ petri dishes. A5 mm mycelial plug of 3 day old culture was taken using a cork borer and placed at the centre of petri plate. The plates were kept in incubator at $28^{\circ} \mathrm{C}$ and three replications were maintained. The radial growth of Trichoderma asperellum was measured after $72 \mathrm{hrs}$ of incubation and percent growth inhibition was calculated by the following formula C-T/ C $\mathrm{x} 100$ where $\mathrm{C}$ is the growth in control and $\mathrm{T}$ is the growth in treatment.

\section{Results and Discussion}

The isolate was green coloured on petriplate, the conidiophores were highly branched and terminated with sub globose phialides. The phialides were flask shaped and constricted at the tip. Based on these morphological characteristics and microscopic observations, it was identified as belonging to the genus Trichoderma (Fig.1). Fungal members of Trichoderma are known to be cosmopolitan and grow in different substrates, including infected or degrading plant debris, decaying wood etc. (Garcia-Gaza et al., 1997). They are known as biocontrol agents, and are very much interactive in soil and roots (Zghair et al., 2014). They show rapid multiplication and reproduction, besides hyperparasitism. Trichoderma is known to be involved in biotrophic mycoparasitic associations, and the

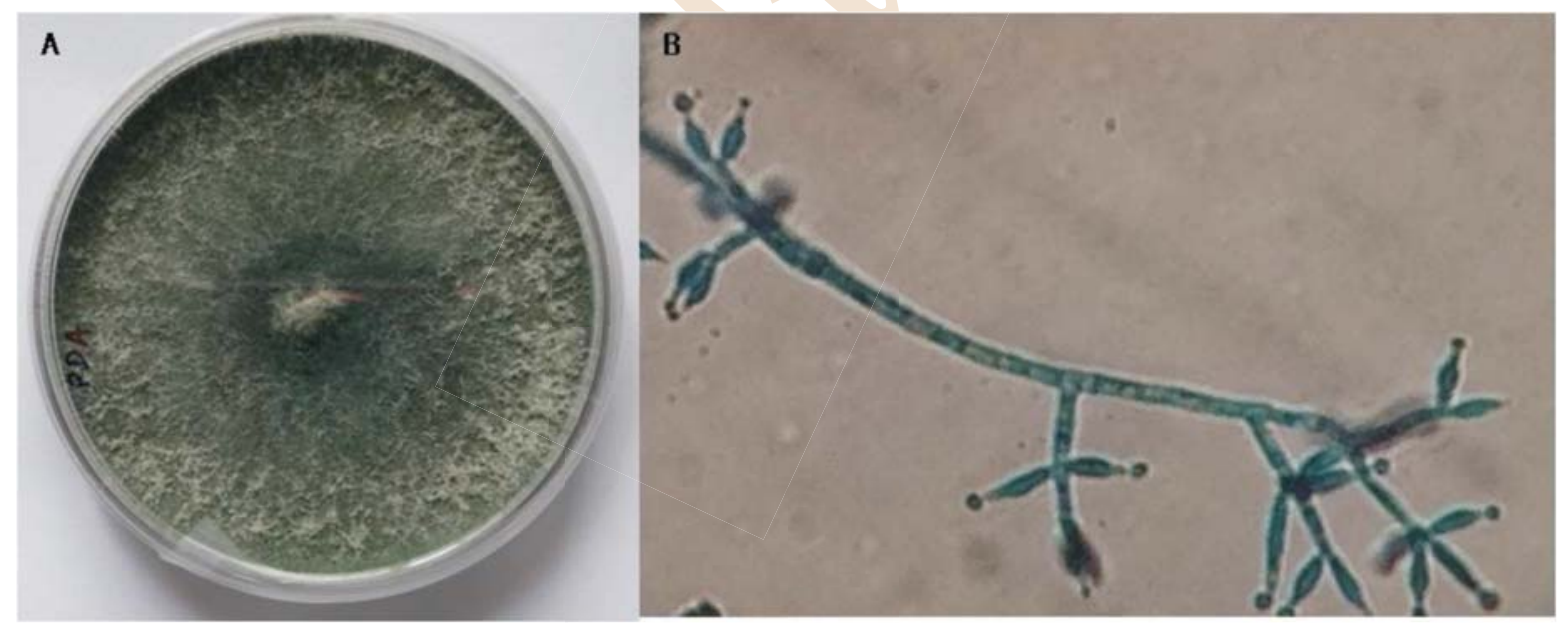

Fig. 1 : (A) Colony morphology; (B) Microphotograph of Trichoderma isolate 


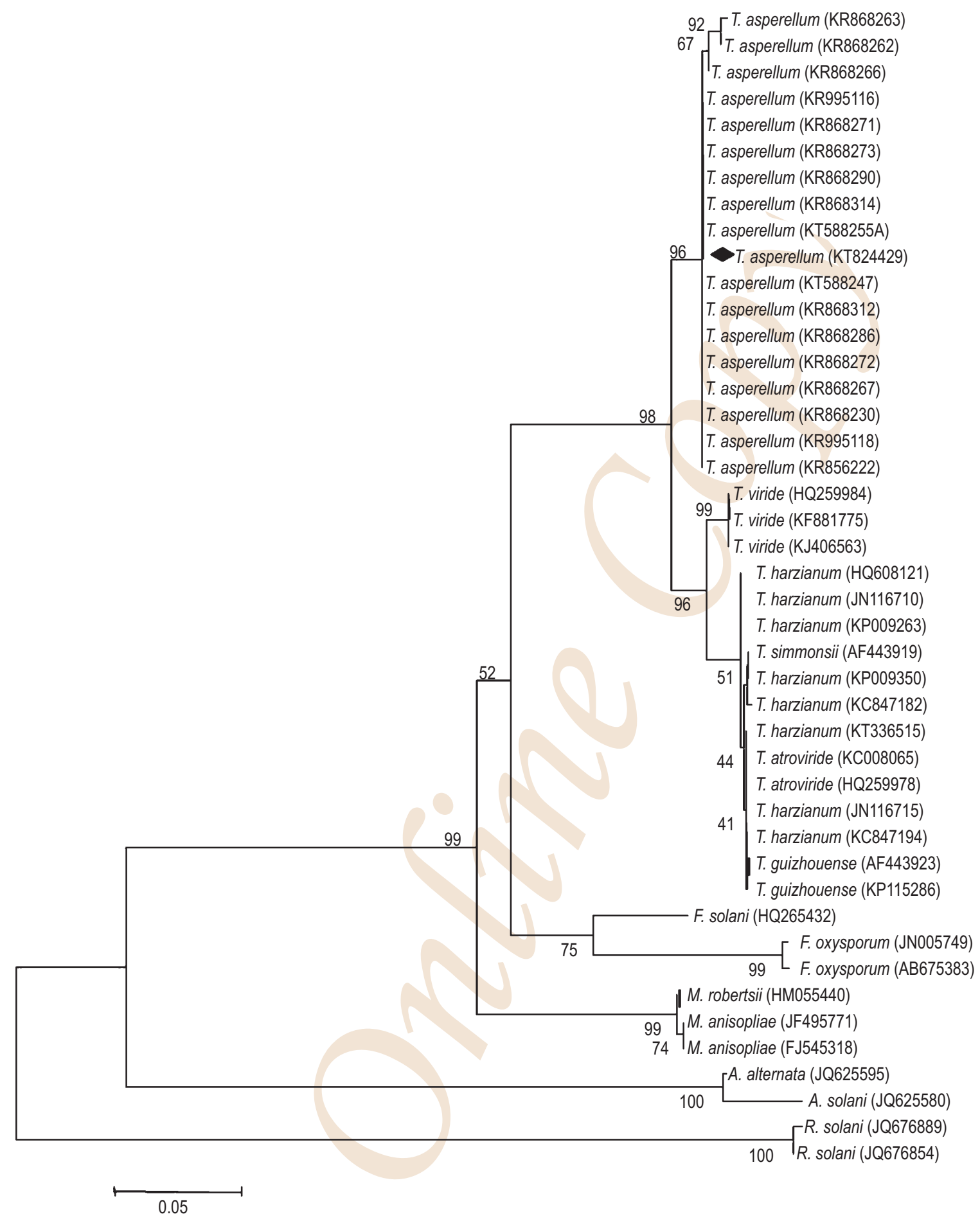

Fig. 2 : Phylogenetic tree based on the comparison of ITS sequences of T. asperellum and other Trichoderma spp. and fungi registered in GenBank. The numbers in parentheses represent the accession numbers in GenBank. The numbers in each branch points denote the percentages supported by bootstrap. The scale bar represents 0.05 substitutions per nucleotide position 


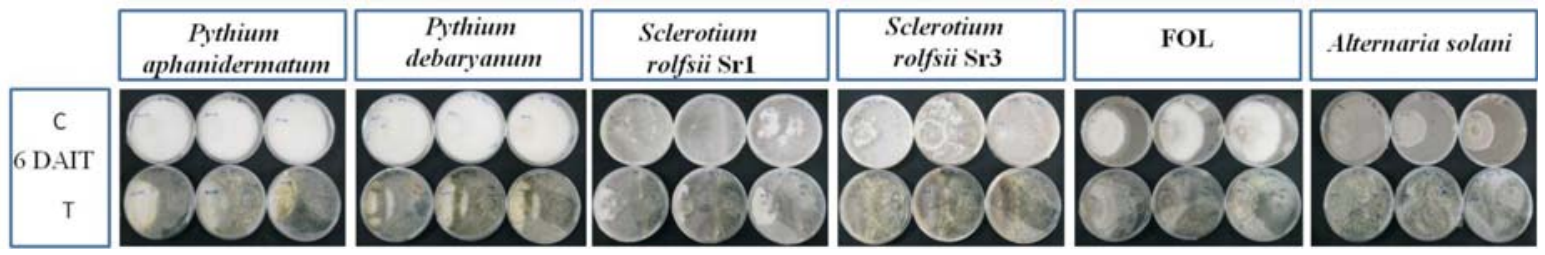

Fig. 3 : Antagonism of Trichoderma asperellum against different plant pathogens. FOL-Fusarium oxysporum f.sp. lycopersici; DAIT-Days after inoculation of T. asperellum; C-Control; T-Treatment
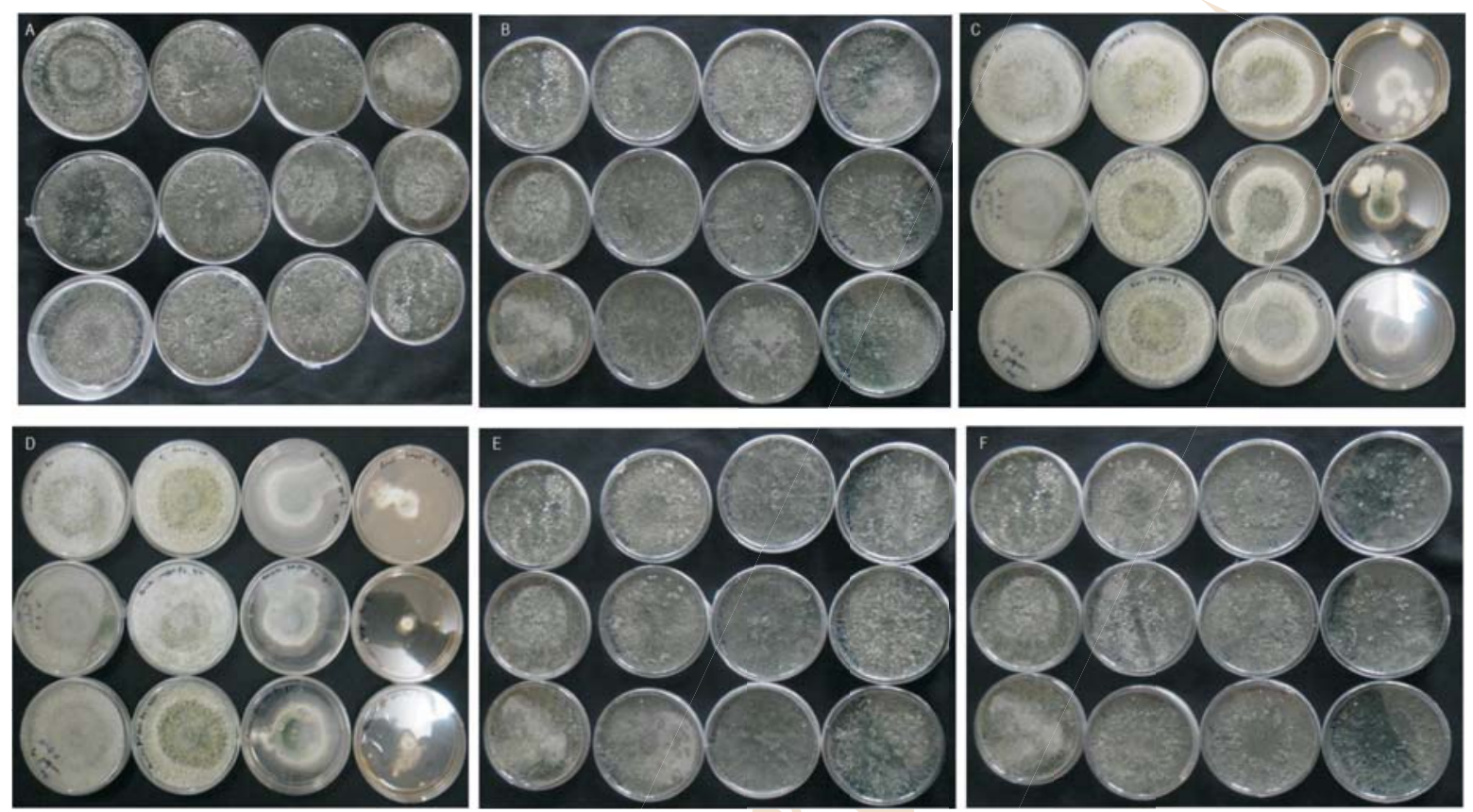

Fig. 4 : Compatibility of Trichoderma asperellum with different fungicides. A: Curzate M8; B: Ridomil Gold; C: Sixer ; D: Bavistin ; E: Amistar; F: Indofil M 45. Right to Left: Control, 100, 200,300 ppm concentrations

isolate in the present study is such an example. Different species of Trichoderma (Hypocreales, Ascomycota) have been widely used as biocontrol agents against plant pathogens (Samuels 1996; Kumar and Gupta, 1999; Harman, 2000).

Out of four media tested, Trichoderma isolate grew rapidly on PDA and OMA with a radial growth of $4.5 \mathrm{~cm}$ after $72 \mathrm{hrs}$ of incubation. On CMA and Czapekdox agar, the radial growth was 2.82 and $4.33 \mathrm{~cm}$, respectively. The Trichoderma isolate was purified on PDA and used for extraction of DNA. PCR based amplification of internally transcribed spacer (ITS) region of the isolate and sequencing was undertaken. In silico analysis revealed $100 \%$ similarity to Trichoderma asperellum. The phylogenetic analysis revealed the close clustering of the isolate with other T. asperellum isolates (Fig. 2). Based on cultural, morphological and molecular characteristics, the isolate was identified as $T$. asperellum. The sequence was deposited at GenBank (NCBI) with an accession no. KT824429. Several $T$. asperellum isolates have been reported as multifaceted bioagents (de los Santos- Villalobos et al., 2013; Marcello et al., 2010; Tondje et al., 2007).

T. asperellum isolates have been reported as multifaceted bioagents, and as elicitors of plant immune responses (de los Santos- Villalobos et al., 2013; Marcello et al., 2010; Tondje et al., 2007). The antagonistic capability of $T$. asperellum was assessed through in vitro confrontation studies. $T$. asperellum caused significant reduction in the mycelial growth of the pathogens tested (Fig. 3). The highest inhibition values of 43.57, 38.16, 42.56 and $54.87 \%$ were obtained for Pythium aphanidermatum, P. debaryanum, Sclerotium rolfsii Sr1 and Sclerotium rolfsii Sr3, respectively, after 6 days of $T$. asperellum inoculation. This isolate also inhibited mycelial growth of Fusarium oxysporum f.sp. lycopersici and Alternaria solani to the extent of 26.27 and $24.17 \%$ after 5 days and parasitisation after 6 days of incubation (Table 1). The isolate used in the present study 
Table 1 : Inhibitory activity of the Trichoderma isolate against selected phytopathogenic fungi, as measured in dual culture assays after 5 and 6 days of incubation

\begin{tabular}{lll}
\hline \multirow{2}{*}{ Pathogen } & \multicolumn{3}{c}{ Mycelial inhibition (\%) } \\
\cline { 2 - 3 } & \multicolumn{1}{c}{$\mathbf{5 \text { day }}$} & \multicolumn{1}{c}{$\mathbf{6 \text { day }}$} \\
\hline Pythium aphanidermatum & $38.71 \pm 2.24$ & $43.57 \pm 4.68$ \\
Pythium debaryanum & $37.43 \pm 2.78$ & $38.16 \pm 2.60$ \\
Sclerotium rolfsii Sr-1 & $47.43 \pm 0.67$ & $42.56 \pm 0.92$ \\
Sclerotium rolfsii Sr-3 & $57.69 \pm 0.44$ & $54.87 \pm 0.67$ \\
Fusarium oxysporumf.sp. lycopersici & $26.27 \pm 10.06$ & Parasitisation \\
Alternaria solani & $24.17 \pm 13.15$ & Parasitisation \\
CD (p<0.05) & 25.15 & 12.32 \\
\hline
\end{tabular}

Table 2 : Fungicides used for compatibility studies with Trichoderma asperellum

\begin{tabular}{llll}
\hline Product name & Formulation type & Active constituent & Company \\
\hline Curzate M8 & WP & Cymoxanil (8\%)+ mancozeb 64\% & Dupont \\
Ridomil Gold & WP & Metalaxyl $4 \%+$ mancozeb 64\% & Syngenta \\
Sixer & WP & Carbendazim 12\%+Mancozeb 63\% & DhanukaAgritech Ltd. \\
Bavistin & WP & Carbendazim $50 \%$ & BASF \\
Amistar & SC & Azoxystrobin $(23.1 \%$ w/w) & Syngenta \\
Indofil M 45 & WP & Mancozeb 75\% & Indofil \\
\hline
\end{tabular}

was effective against all the six tested plant pathogens causing severe loss to vegetable crops (Table 1). Yedidia et al. (2003) reported that $T$. asperellum gives protection against soil borne, as well as foliar pathogens. It effectively managed the Pseudomonas syringae pv. lachrymans infection in cucumber by inducing systemic resistance towards a foliar pathogen. It also drastically controlled the sclerotium rolfsii infecting bean and chickpea plants (Pacheco et al., 2016; Prajapati et al., 2015). Such fast growing bioagents have additional advantage in competing with the pathogens for space and nutrients (Simon and Sivasithaparam, 1988; Benitez et al., 2004). T. asperellum isolate under study was fast growing in comparison to all the pathogens. Even though was inoculated two days after the pathogens were inoculated, it overgrew and completely parasitized them. Kumar et al. (2012) reported that $T$. viride inhibited mycelial growth of $S$. rolfsii more than $50 \%$. In the present study, $54.87 \%$ mycelial inhibition of $S$. rolfsii $\mathrm{Sr} 3$ was recorded (Table 1).

Compatibility of bioagent is very important to reduce the use of chemical fungicides and effective management of fungal pathogens (Elshahawy et al., 2016). The details of the fungicides used in the study are given in Table 2. T. asperellum exhibited $100 \%$ compatibility with Mancozeb, Azoxystrobin, Cymoxinil+Mancozeb, Metalxyl+Mancozeb at 100, 200 and 300 ppm, (Fig. 4). The percent compatibility of $98.15,74.82$ and 50.38 $\%$ with Carbendazimat 100, 200 and 300 ppm concentrations was also recorded. The compatibility percentage for Carbendazim and Mancozeb was $90.38,70.38$ and $47.41 \%$ at 100,200 and 300 ppm, respectively. Hjeljord and Tronsmo (1998) reported that Trichoderma species can use fungicides as a source of nutrient upto certain concentration levels. Fungicides at low concentrations induce stress and weaken the pathogen by making its propagules susceptible to attack by bioagent (Hjeljord and Tronsmo, 1998); increase in the concentration of fungicide inhibits the fungal growth. Carbendazim and combination of carbendazim and mancozeb reduced the growth of $T$. asperellum at higher concentration. Efficacy of bioagent is augmented when they are used in combination with fungicides at lower concentration (Silimela and Korsten, 2001). Integration of bioagents with chemical fungicides reduces seed infection more effectively than they are used alone (Srinivas and Ramakrishnan, 2002).

In the present study, Trichoderma asperellum isolate was effective against six phytopathogenic fungi-Pythium aphanidermatum, $P$. debaryanum, Sclerotium rolfsii Sr1, S. rolfsii Sr3, Fusarium oxysporum f.sp. Iycopersici and Alternaria solani. T. asperellum exhibited $100 \%$ compatibility with Mancozeb, Azoxystrobin, Cymoxinil+Mancozeb, Metalxyl+Mancozeb at 100, 200 and $300 \mathrm{ppm}$. The presence of hyperparasitism and competitive ability in the isolate makes it an ideal candidate for inclusion in integrated disease management practices.

\section{Acknowledgment}

The authors are thankful to ICAR-Indian Institute of Vegetable Research, Varanasi for providing necessary facilities towards undertaking this study. 


\section{References}

Abo-Elyousr, K. A. M., I. Sobhy, I. Abdel-Hafez and I. Abdel-Rahim: Isolation of Trichoderma and evaluation of their antagonistic potential against Alternaria porri. J. Phytpathol., 162, 567-574 (2014).

Benítez, T., A.M. Rincón, M.C. Limón and A.C. Codón: Biocontrol mechanisms of Trichoderma strains. Int. Microbiol., 7, 249260(2004).

Bhai Suseela, R. and J. Thomas: Compatibility of Trichoderma harzianum (Riai.) with fungicides, insecticides and fertilizers. Ind. Phytopathol., 63, 145-148(2010).

Brito Joao, P.C., H.S. Marcelo, Ramada, Mariana TQ de Magalhães, L.P. Silva and J.U. Cirano: Peptaibols from Trichoderma asperellum TR356 strain isolated from Brazilian soil. Springer Plus, 3, 600 doi:10.1186/2193-1801-3-600 (2014).

de los Santos-Villalobos, S., D. A. Guzmàn-Ortiz, M. A. Gomez-Lim, J. P. Délano-Frier, S. de-Folter, P. Sànchez-Garía and J.J. Peña Cabriales: Potential use of Trichoderma asperellum (Samuels, Liechfeldt et Nirenberg) T8a as a bio-logical control agent against anthracnose in mango (Mangifera indica L.). Biol. Con., 64, 37-44 (2013).

Doyle, J.J. and J.L. Doyle: A rapid DNA isolation procedure for small quantities of fresh leaf tissue. Phytochem. Bull., 19, 11-15(1987).

Dubey, S.C. and B. Patil: Determination of tolerance in Thanetophorus cucumeris, Trichoderma viridae, Gliocladium virens and Rhizobium sp. to fungicides. Ind. Phytopathol., 54, 98-101(2001).

Edington, L. V., K. L. Khew and G. I. Barron: Fungitoxic spectrum of benzimidazole compounds. Phytopatholgy, 61, 4-44 (1971).

El Komy Mahmoud, H., A.A. Saleh, A. Eranthodi and Y.Y. Molan: Characterization of novel Trichoderma asperellum isolates to select effective biocontrol agents against tomato Fusarium wilt. Plant Pathol. J., 31, 50-60 (2015).

Elshahawy, I.E., K.H.E. Haggag and H. Abd-El-Khair: Compatibility of Trichoderma spp. with seven chemical fungicides used in the control of soil borne plant pathogens. Res. J. Pharma. Biol. Chem. Sci., 7, 1771-1785(2016).

García-Garza, J.A., R.D. Reeleder and T.C. Paulitz:. Degradation of sclerotia of Sclerotinia sclerotiorum by fungus Gnats (Bradysia copropila) and the biocontrol fungi Trichoderma spp. Soil Biol. Biochem., 29, 123-129(1997).

Hamed Eman, R., M.A. Hassan, E.A. Ghazi., N.G. El-Gamal and H.S. Shehata: Trichoderma sp. isolated from salinity soil using rice straw waste as biocontrol agent for cowpea plant pathogens. J. Appl. Pharma. Sci., 5, 91-98(2015).

Harman, G.E.: Myth and dogmas of biocontrol; changes in perceptions derived from research on Trichoderma harzianum T-22. Plant Dis., 84, 377-393(2000).

Harman, G.E., C.R. Howell, A. Viterbo, I. Chet and M. Lorito: Trichoderma species--opportunistic, a virulent plant symbionts. Nat. Rev. Microbiol., 2, 43-56(2004).

Hjeljord, L. and A. Tronsmo: Trichoderma and Gliocladium in biological control: An overview. In: Trichoderma and Gliocladium-Enzymes, Biological Control and Commercial Applications (Eds.: G.E. Harma and C.P. Kubicek). Taylor \& Francis Ltd., London, pp. 131151(1998).

Holajjer, P., A. Kamra, H.S. Gaur and M. Manjunath: Potential of cyanobacteria for biorational management of plant parasitic nematodes:Areview. Crop Prot., 53,147-151(2013).
Kamal, A.M., E.S. Abo-Elyousr, M. Hashem and E.H. Ali: Integrated control of cotton root rot disease by mixing fungal biocontrol agents and resistance inducers. Crop Prot., 28, 295-301(2009).

Kumar, A. and J.P. Gupta: Variation in enzyme activity of tubeconazole tolerant biotypes of Trichoderma viride. Ind. Phytopathology, $\mathbf{5 2}$, 263-266(1999).

Kumar, K., N. Amaresan, S. Bhagat, K. Madhuri and R.C. Srivastava: Isolation and characterization of Trichoderma spp. for antagonistic activity against root rot and foliar pathogens. Ind. J. Microbiol., 52 , 137-144(2012).

Marcello, C.M., A.S. Steindorff, S.P. Silva, R.N. Silva, L.A.M. Bataus and C. J. Ulhoa: Expression analysis of the exo- $\beta$-1,3-glucanase from the mycoparasitic fungus Trichoderma asperellum. Microbiol. Res., 165, 75-81(2010).

Morton, D. J. and W. H. Stroube: Antagonistic and stimulating effects of soil micro-organism of Sclerotium. Phytopathology, 45, 417-420 (1955).

Mukherjee, M., P. K. Mukherjee, B.A. Horwitz, C. Zachow, G. Berg and S. Zeilinger: Trichoderma-plant-pathogen interactions: Advances in genetics of biological control. Ind. J. Microbiol., 52, 522-529 (2012).

Nene, Y.L. and P. N. Thapliyal: Fungicides in Plant Disease Control. Oxford and IBH Publishing Co., New Delhi, India (1993).

Pacheco, K.R. and B.S.M. Viscardi: Efficacy of Trichoderma asperellum, T. harzianum, T. longibrachiatum and T. reesei against Sclerotium rolfsii. BioSci. J., 32, 412-421(2016).

Pokhare, S. S., J. Berliner, T. Adak, U. Kumar and A. Mukherjee: Entomopathogenic Nematodes: Insect biocontrol agents. Indian Farm., 65, 20-23 (2015).

Prajapati, B.K., J.K. Patel and R.K. Patil: Bioefficacy of Trichoderma sp. against Sclerotium rolfsii sacc. an incitant of collar rot of chickpea in vitro. The BioScan, 10, 1745-1748 (2015).

Rao, K.L.N.M., K.S. Raju and H. Ravisankar: Antifungal properties of native Trichoderma isolates against Sclerotium rolfsii and Pythium aphanidermatum infecting tobacco J. Environ. Biol., 36, 1349$1353(2015)$

Samuels, G.J.: Trichoderma: A review of biology and systematics of the genus. Mycological Res., 100, 923-935(1996).

Silimela, M. and L. Korsten: Alternative methods for preventing pre and post-harvest diseases and sunburn on mango fruits. S.A. Mango Growers Association Yearbook, 21, 39-43 (2001).

Simon, C. and M. Sivasithaparam: Interaction among Gaeumannomyces graminum var. tritci Trichoderma koningii and soil bacteria. Can. J. Microbiol., 34, 871-876 (1988).

Shaiesta, S., S. Nasreen and P.A. Sheikh: Cultural and morphological characterization of Trichoderma spp. associated with green mold disease of Pleurotus spp. in Kashmir. Res. J. Microbiol., 7, 139144 (2012).

Srinivas, P. and G. Ramakrishnan: Use of native microorganisms and commonly recommended fungicides in integrated management of rice seed borne pathogens. Annals Plant Prot. Sci., 10, 260-264 (2002).

Sriram, S., M.J. Savitha, H.S. Rohini and S. K. Jalali: The most widely used fungal antagonist for plant disease management in India, Trichoderma viride is Trichoderma asperellum as confirmed by oligonucleotide barcode and morphological characters. Curr. Sci., 104, 1332-1340 (2013).

Tamura, K., D. Peterson, N. Peterson, G. Stecher, M. Nei and S. Kumar: MEGA5: Molecular evolutionary genetics analysis using maximum 
likelihood, evolutionary distance and maximum parsimony methods. Mol. Biol. Evol., 28, 2731-2739 (2011)

Thompson, J.D., D.G. Higgins and T.J. Gibson: Clustal W: Improving the sensitivity of progressive multiple sequence alignment through sequence weighting, position-specific gap penalties and weight matrix choice. Nucleic Acids Res., 22, 4673-4680 (1994).

Thoudam, R. and B.K. Dutta: Compatibility of Trichoderma atroviride with fungicides against black rot disease of tea: An in vitro study. J. Int. Aca. Res. Multidiscipl., 2, 25-33 (2014).

Tondje, P.R., D.P. Roberts, M.C. Bon, T. Widmer, G.J. Samuels, A. Ismaiel, A.D. Begoude, T. Tchana, E. Nyemb-Tshomb, M. NdoumbeNkeng, R. Bateman, D. Fontem and K.P. Hebbar: Isolation and identification of mycoparasitic isolates of Trichoderma asperellum with potential for suppression of black pod disease of cacao in Cameroon. Biol. Cont., 43, 202-212 (2007).

Triveni, S., R. Prasanna, A. Kumar, N. Bidyarani, R. Singh and A.K. Saxena: Evaluating the promise of Trichoderma and Anabaena based biofilms as multifunctional agents in Macrophomina phaseolina-infected cotton crop. Biocont. Sci. Technol., 25, 656670 (2015).
White, T.J., T. Bruns, S. Lee and J. Taylor: Amplification and direct sequencing of fungal ribosomal RNA genes for phylogenetics. In: PCR protocols: A guide to methods and applications (Eds.: M.A. Innis, D.H. Gelfand, J.J. Sninsky and T.J. White). New York:Academic Press, pp.315-322 (1990).

Wedajo, B.: Compatibility studies of fungicides with combination of Trichoderma species under in vitro conditions. Virol. Mycol., 4, 149(2015). doi:10.4172/2161-0517.1000149.

Yedidia, I., M. Shoresh, Z. Kerem, N. Benhamou, Y. Kapulnik and I. Chet: Concomitant induction of systemic resistance to Pseudomonas syringae pv. lachrymans in cucumber by Trichoderma asperellum (T-203) and accumulation of phytoalexins. Appl. Environ. Microbiol., 69, 7343-7353 (2003).

Zghair, Q.N., A. A. Lal, M.M. Mane and S. Simon: Effect of bioagents and fungicide against earlyblight disease of tomato (Lycopersicon esculentumL.). Int. J. Plant Protec., 7, 330-333 (2014).

Zhang, F., Z. Zhu, X. Yang, W. Ran and Q. Shen: Trichoderma harzianum T-E5 significantly affects cucumber root exudates and fungal community in the cucumber rhizosphere. Appl. Soil Ecol.,72, 41$48(2013)$ 